REVISTA ANDALUZA DE ANTROPOLOGÍA

NÚMERO 15: ACTIVIDADES TURÍSTICAS, CIUDAD Y PATRIMONIO CULTURAL: MIRADAS CRÍTICAS. TOURIST ACTIVITIES, CITY AND CULTURAL HERITAGE: CRITICAL GLANCES

SEPTIEMBRE DE 2018

ISSN 2174-6796

[pp. $\mathbf{x}-\mathrm{xx}$ ]

http://dx.doi.org/10.12795/RAA.2018.15.13

\title{
LUNDSTEEN, Martin (2017). Espai, capital i cultura: el cas de la mesquita de Premià de Mar. Barcelona: Pol·len Edicions, 208 pp.
}

\section{José A. Mansilla López}

Departamento de Ciencias Sociales y Comunicación

Escuela Universitaria de Turismo Ostelea (Universitat de Lleida) y Observatori d’Antropologia del Conflicte Urbà

En el Tomo I de su obra cumbre, El Capital, Karl Marx introduce una de las metáforas más exitosas y con mayor proyección de su edificio teórico: el fetichismo de la mercancía. Para el filósofo alemán, los productos del trabajo humano, las mercancías, parecen mostrar "una relación social [...] al margen de los productores" (1990: 23), haciendo invisibles las relaciones sociales de explotación características del modo de producción capitalista. Autores como David Harvey (2008a) llevan hasta sus últimas consecuencias esta aproximación al carácter fantasmal de la mercancía cuando, siguiendo a Lefebvre (1969), equiparan ésta a la ciudad contemporánea. Lejos de haberse convertido en el espacio por excelencia de la sociabilidad humana y el valor de uso, elementos consustanciales al tan manoseado derecho a la ciudad, las ciudades han devenido factores inextricables a la continuidad de los procesos de acumulación. Continuando con Harvey (2008b: 23), este derecho sería "mucho más que la libertad individual de acceder a los recursos urbanos: se trata del derecho a cambiarnos a nosotros mismos cambiando la ciudad [...], un derecho común antes que individual, ya que esta transformación depende inevitablemente del ejercicio de un poder colectivo para remodelar los procesos de urbanización”. De esta forma, la propuesta del geógrafo inglés pasaría, primero, por relevar las relaciones sociales insertas, y aparentemente ocultas, tras las dinámicas urbanizadoras y, segundo, por tomar las riendas de las mismas de forma colectiva. El papel de los investigadores 
sociales pasaría, así, por ser capaces de desentrañar la realidad oculta tras los procesos sociales urbanos actuando, si se me permite la comparación y continuando con la referencia marxista, como auténticos exorcistas de la ciudad (Mansilla, 2017).

El libro de Martin Lundsteen, Espai, Capital i Cultura: el cas de la mesquita de Premià de Mar, abunda, precisamente, en este sentido. De este modo, tras un conflicto presentado -y enfrentado-, tanto por parte de los distintos niveles administrativos del Estado español, como por determinados medios de comunicación, como derivado de determinados problemas de convivencia vecinal, intolerancia con la inmigración proveniente del norte de África, prácticas xenófobas, etc., se encontrarían, más bien, las consecuencias de las dinámicas socio-espaciales ocurridas durante las últimas décadas en el mencionado municipio de la comarca del Maresme, en Barcelona.

Premià de Mar tiene una historia similar a la de tantas otras poblaciones catalanas. Donde hace un par de siglos había únicamente un pequeño pueblo dedicado a la agricultura y la pesca, encontramos, hoy día, una ciudad-dormitorio del Área Metropolitana de la capital de Catalunya. Los cambios acontecidos en Premià durante estos años se vieron influenciados por dos factores fundamentales: en primer lugar, por el proceso de industrialización acelerado que vivió el área a partir de la segunda mitad de los novecientos -de hecho, la primera línea ferroviaria del Estado, Barcelona-Mataró, pasaba justo por su término municipal- $y$, en segundo lugar, por la consiguiente mano de obra que, sobre todo a partir de los años 60 del pasado siglo, se asentó en el municipio en respuesta a las necesidades de dicha industria. Estos procesos determinaron una ciudad con unos límites territoriales y sociodemográficos muy claros: un centro histórico de población principalmente catalana y cierta diversidad arquitectónica, desde pequeños palacetes o lujosas casas burguesas, hasta viviendas construidas según el modo tradicional de la zona, y un eixample de nueva construcción poblado de bloques edificados durante el tardofranquismo, a veces de escasa calidad y, sobre todo, con una notoria falta de equipamientos y servicios para unos vecinos y vecinas provenientes de otras partes de la península.

Ambas zonas se encuentran separadas por la Gran Via de Lluis Companys y, muy cerca de la misma, en el barrio del Maresme, en el eixample, la que podríamos denominar la manzana de la discordia, aquella conformada por las calles Joan Prim, de la Mercè, Cisa y el Pasaje Prim. En la misma, una asociación musulmana, la Associació Islàmica At-Tauba (AIAT), conformada por creyentes que venían desarrollando sus prácticas religiosas desde el año 1984 en un local bajo de la calle Núria, también en la zona, se fijan para construir la que pretendía ser la primera mezquita de Catalunya, allá por el año 1997. A partir de ese momento, en medio de un proceso que va creciendo en magnitud y escala conforme se suceden los acontecimientos -y los errores, como muy bien señala el autor-, distintos actores van incorporándose a una historia que, lamentablemente, más de veinte 
años después, sigue sin tener una solución satisfactoria. Además de la mencionada asociación, el propio Ayuntamiento de Premià de Mar, con distintos grupos políticos al mando, la Generalitat de Catalunya, el Consell Islàmic Cultural de Catalunya (CICC), las Asociaciones de Vecinos y Vecinas del pueblo, distintos colectivos y organizaciones, como la Plataforma "No a la Mesquita al Carrer Joan Prim", SOS Racisme o la Coordinadora "Premià per la Convivència", junto a partidos políticos de tintes claramente racistas, como Plataforma per Catalunya ( $\mathrm{PxC}$ ), sumados a unos medios de comunicación que actuaron como potente altavoz de unos y otros, acabaron situando el problema en el ámbito de lo que podríamos denominar, siguiendo al autor, "diferencialismo cultural" (Lundsteen, 2017: 138). Una visión de la cultura, ésta, bastante singular, pues parece presentarse como heredera del concepto de raza, el cual, aunque deslegitimado completamente por antropólogos como Levi-Strauss (1999) hace décadas, sobreviviría bajo la sombra de una aproximación rígida, estanca y, sobre todo, excluyente, aunque útil para los dominadores al permitir el ejercicio de cierta violencia simbólica (Bourdieu,1990).

De este modo, en el marco de la nueva gobernanza urbana (Harvey, 1989) y su pariente cercano, los flujos migratorios, aquellos dispositivos discursivos destinados a situar de forma hegemónica la inmigración como un problema cultural, sin cuestionar nunca las desigualdades sociales, las condiciones de explotación y las diferencias, cada vez más pronunciadas, que ocasiona el neoliberalismo, permitirían a los distintos actores con capacidad de incidencia, llevar a cabo sus acciones y políticas bajo el prisma de la necesidad del fomento de la concordia, la convivencia o mediante una tolerancia presentada, siguiendo a Delgado, como "el peor enemigo contra el que se enfrenta el antirracismo", que no es tanto el racismo, "como la irrefrenable tendencia que él mismo experimenta hacia su total trivialización” (1998). Es justamente aquí donde el autor de la investigación interviene exorcizando las mencionadas políticas diferencialistas para, desde la economía política, mostrar la base material que recorre el proceso en torno a la construcción de la mezquita. Así, en un trabajo de campo llevado a cabo varios años después de que los acontecimientos principales tuvieran lugar, entre 2008 y 2009, lo que en un principio podría aparecer a los ojos de todos como un problema cultural, se acaba presentando como un nuevo ejemplo de lucha por el espacio urbano (Salcedo, 2007), donde un vecindario tradicionalmente olvidado ve como peligran ciertas mejoras largamente reclamadas, mientras que els nouvinguts, vecinos y vecinas de clase media y media-alta provenientes de Barcelona, creen, a su vez, ver peligrar el valor de sus sacrosantas propiedades.

Sin embargo, la principal virtud del texto, ser capaz de presentar unos hechos aparentemente evidentes bajo una perspectiva contrahegemónica, aparece también como una de sus principales flaquezas pues, aunque la intención del autor queda patente desde el principio cuando describe sus objetivos, el capital del título apenas aparece esbozado 
a lo largo del libro. De esta forma, se echa en falta una mayor concreción y análisis del protagonismo del propio capital y su correlación, el valor de cambio, ya que, cuando éste aparece, lo hace principalmente en boca de sus protagonistas, desligado aquí y allá, habiendo que esperar hasta el capítulo de conclusiones para que su importancia se haga evidente. Las razones de esto podrían estar en la brevedad del texto, apenas doscientas páginas, las limitaciones del trabajo de campo, solo cuatro meses, o en el motivo que da origen al libro, la Tesina de Fin de Máster del autor. Por otro lado, también se aprecia una cierta ligereza en la edición del texto, pues aparece plagado de pequeños errores tipográficos. Sin embargo, es necesario resaltar que estas cuestiones no quitan un ápice de valor a la investigación realizada.

El trabajo de Martin Lundsteen en torno al conflicto generado por la construcción de una mezquita en el municipio de Premià de Mar continua una línea de investigaciones en marcha, tanto dentro como fuera de Catalunya y el Estado español, que manifiestan la necesidad de volver a recoger los instrumentos de la economía política a la hora de analizar el papel que juegan hoy día las ciudades en el marco general del capitalismo. Son necesarios, por tanto, más textos como el presente ya que, solo así, aproximaciones críticas hoy casi desaparecidas del panorama académico alcanzaran el protagonismo que se merecen, sirviendo, además, como útiles herramientas en la lucha que supone hoy día la vida en la ciudad.

\section{Bibliografía}

Bourdieu, P. (1990) Sociología y cultura. México DF: Grijalbo.

Delgado, M. (1998) "El derecho a la indiferencia". El Cor de les Apariències http:// manueldelgadoruiz.blogspot.com.es/2011/02/el-derecho-la-indiferencia-articulo.htm [Consultado el 5 de febrero de 2018].

Harvey, D. (1989) "From managerialism to entrepreneuralism: The tranformation in urban governance in late capitalism" Geografiska Annaler, 71B, n 1, pp. 3-17.

Harvey, D. (2008a) París, capital de la modernidad. Madrid: Ed. Akal.

Harvey, D. (2008b) “El derecho a la ciudad". New Left Review, n53, pp. 23-39.

Lefebvre, H. (1969) El derecho a la ciudad. Barcelona: Ediciones Península.

Levi-Strauss, C. (1999) Raza y Cultura. Madrid: Altaya.

Lundsteen, M. (2017) Espai, capital i cultura: el cas de la mesquita de Premià de Mar. Barcelona: Pol-len Edicions. 
Mansilla, J. A. (2017) "El antropólogo como exorcista”. El Antropólogo Perplejo https:// antroperplejo.wordpress.com/2016/09/26/el-antropologo-como-exorcista/ [Consultado el 5 de febrero de 2018].

Marx, K. (1990) El Capital, Tomo I. Moscú: Editorial Progreso.

Salcedo, R. (2007) "La lucha por el espacio urbano". En Olga Segovia (coord.) Espacios Públicos y Construcción Social. Santiago de Chile: SUR, pp. 69-78. 